\title{
Anthers colonized by fungi as the nearest source to initiate strawberries postharvest rot
}

\section{Monteiro FP $^{1}$, Valmorbida $\mathbf{J}^{1}$, Wamser $\mathrm{AF}^{1}$, Ogoshi $\mathbf{C}^{1}$, Cardoso $\mathbf{D A}^{2}$, Perazolli $\mathbf{V}^{3}$}

\begin{abstract}
${ }^{1}$ Researchers at the EPAGRI - Agricultural Research and Rural Extension Enterprise of Santa Catarina, Abílio Franco, 1500, Bom Sucesso, PO Box 591, Zip code 89.501-032, Caçador, Santa Catarina, Brazil

${ }^{2}$ Undergraduate student at the UFSC - Universidade Federal de Santa Catarina, Bernardo Olsen, 400, Centro, Canoinhas, Santa Catarina, Brazil

${ }^{3}$ Undergraduate student at the UNOESC - Universidade do Oeste de Santa Catarina, Paese, 198, Universitário, Videira, Santa Catarina, Brazil
\end{abstract}

Monteiro FP, Valmorbida J, Wamser AF, Ogoshi C, Cardoso DA, Perazolli V 2020 - Anthers colonized by fungi as the nearest source to initiate strawberries postharvest rot. Plant Pathology \& Quarantine 10(1), 53-58, Doi 10.5943/ppq/10/1/6

\begin{abstract}
Strawberry cultivation is expanding in Brazil, but few tactics are employed to extent the shelf-life of the strawberries fruits, which are affected by postharvest fungi that cause rot. To clarify how this rot progress, the objective of this work was to study the relationship between fungi that colonize anthers and rot of strawberry fruits during postharvest. The incidence of fungi in the strawberry anthers, the disease progress in strawberry fruits with infested anthers and in vitro fungicides efficiency against Cladosporium sp. were performed. Cladosporium sp. was found in $100 \%$ of the plants and in approximately $65 \%$ of the flowers during strawberry cultivation in a semi-hydroponic system. From 148 anthers without fungal signs placed into Petri dishes containing PDA, 94 were contaminated with Cladosporium and two of them had Penicillium sp. All 40 strawberry fruits which had Cladosporium sp. infesting their anthers were rotten by this fungus after nine days. As the most recurrent fungus was Cladosporium, the most efficient fungicides to control this fungus were azoxystrobin + diphenoconazole, boscalide + cresoxim-methyl, metconazole, methyl thiophanate, pyrimenthanil, tebuconazole and trifloxystrobin + tebuconazole at the recommended doses for Botrytis cinerea and Mycosphaerella fragariae. Anther colonization may serve as the nearest source of inoculum to incite postharvest disease, as anthers remain attached to the fruits.
\end{abstract}

Keywords - Blossom rot - Cladosporium - Fragaria x ananassa Duch. - Fusarium

\section{Introduction}

Strawberries are appreciated in the fresh market and as an ingredient that composes various dishes in gastronomy. The world's top five strawberry producers according to the latest sense made in 2017 by the United Nations Food and Agriculture Organization in descending order are China $(3,724,647$ t), United States of America $(1,449,280$ t), Mexico $(658,436$ t), Egypt $(407,240)$ and Turkey (400,167 t) (FAO 2017). Brazil ranks $54^{\text {th }}(3,390 \mathrm{t})$ among strawberry producing countries in the world (FAO 2017). 
Pollen produced by the male part of the flower is a necessary structure for seed formation and propagation of plant species (Kaczmarska et al. 2008). This flower structure is rich in proteins, lipids, carbohydrates, vitamins, amino acids and minerals (Campos et al. 2008), which may be consumed by contaminating fungi. Deterioration of anthers is a naturally occurring process after pollination (Woodson 1991), but most often, the presence of fungi is not evident.

The objective of this work was to study the relationship between anthers fungal colonization and postharvest rot of strawberries.

\section{Materials \& Methods}

\section{Study location and fungal incidence evaluation}

The study was performed in a greenhouse located at 26049'08.1"S and 50 59'14.6"W at the Agricultural Research and Rural Extension Enterprise of Santa Catarina (EPAGRI) at Caçador, Brazil during the years of 2018-2019. Strawberries plants from the cultivar "San Andreas" have been cultivated in double row for two years. During this period, fungus was observed colonizing flower's anthers. To quantify the fungus incidence, 40 plants were evaluated once by observing their anthers to estimate how many anthers were colonized by fungus. After quantifying, fungi were isolated and identified at the phytopathology laboratory based on morphology following the key proposed by Barnett et al. (1972).

\section{Incidence of fungi in anthers without fungal signs}

To account for the fungus in anthers that do not show any signs of the fungus, 148 anthers were collected randomly. Each 10 anthers were inserted into Petri dishes containing PDA (Potato Dextrose - Agar) to allow the fungal growth. After seven days, fungi were identified on the basis of morphology following the key for imperfect fungi (Barnett et al. 1972).

\section{Disease progress in strawberry fruits with infested anthers}

Forty strawberry fruits with anthers naturally infested with Cladosporium sp. were incubated in a humid chamber for nine days. During this period, the number of strawberry fruits rotten by Cladosporium sp. was accounted for to establish the relationship between the Cladosporium found infesting anthers and the rot of the strawberry fruits caused by this fungus.

\section{Proposal of chemical control of the most recurrent pathogen}

Cladosporium mycelial growth was measure under influence of the following chemical fungicides azoxystrobin + diphenoconazole (Dose $120 \mathrm{~mL}$ active ingredient/ha $+75 \mathrm{~mL}$ a. i./ha; spray volume $600 \mathrm{~L})$, trifloxystrobin + tebuconazole $(0,075 \mathrm{~L}$ a.i./ha $+0,15 \mathrm{~L}$ a.i./ha; $1000 \mathrm{~L})$, metconazole (90 mL a.i./100 mL; $1000 \mathrm{~L})$, tebuconazole $(15 \mathrm{~mL}$ a.i./100 mL; $1000 \mathrm{~L})$, methyl thiophanate (49 $\mathrm{mL}$ a.i./100 L; $1000 \mathrm{~L})$, pyrimethanil $(60 \mathrm{~mL}$ a.i./100 mL; $600 \mathrm{~L})$, boscalide + cresoxim-methyl $(400 \mathrm{~mL}$ a.i./ha $+200 \mathrm{~mL}$ a.i./ha; $1000 \mathrm{~L})$, diphenoconazole $(10 \mathrm{~mL}$ a.i./100 L; $200 \mathrm{~L})$, boscalide (400 g a.i./ha; $1000 \mathrm{~L})$, fluazinam $(50 \mathrm{~mL}$ a.i./100 L; $1000 \mathrm{~L})$, azoxystrobin $(8 \mathrm{~g}$ a.i./100 L; $800 \mathrm{~L})$ iprodione $(75 \mathrm{~g}$ a.i./100 L; $1000 \mathrm{~L})$ and procimidone $(50 \mathrm{~g}$ a.i./100 L; $1000 \mathrm{~L})$ to recommend the most efficient fungicide to prevent the rot of the strawberry fruit. The experiment was performed in vitro with Petri dishes containing PDA medium. The fungus was sown in the center of the Petri dishes, which were incubated at $25^{\circ} \mathrm{C}$ and $12 \mathrm{~h}$ photoperiod for 2 weeks. At the end of this period, the mycelial growth was measure.

\section{Statistical analyses}

The results of in vitro fungicides efficiency were submitted to analysis of variance. When significant by the $\mathrm{F}$ test, the means were compared by the Scott-Knott statistical test at $5 \%$ error probability. 


\section{Results}

\section{Fungi found in colonized anthers}

We isolated 3 genera of fungi, Cladosporium, Fusarium and Penicillium. Cladosporium sp. was found in $100 \%$ of the plants and in approximately $65 \%$ of the flowers during strawberry cultivation in a semi-hydroponic system. This fact had not been observed in the previous two years of cultivation. Occasionally, Fusarium sp. and Penicillium were also found infested the anthers (Figs 1, 2). From 148 anthers without fungal signs placed into Petri dishes containing PDA, 94 were contaminated with Cladosporium and two of them had Penicillium. All 40 strawberry fruits which had Cladosporium infesting their anthers were rotten by this fungus after nine days (Fig. 3).

As the most recurrent fungus was Cladosporium, the most efficient fungicides to control this fungus in vitro were azoxystrobin + diphenoconazole, trifloxystrobin + tebuconazole, metconazole, tebuconazole, methyl thiophanate, pyrimenthanil and boscalide + cresoxim-methyl at the recommended doses for $B$. cinerea and $M$. fragariae (Fig. 4).
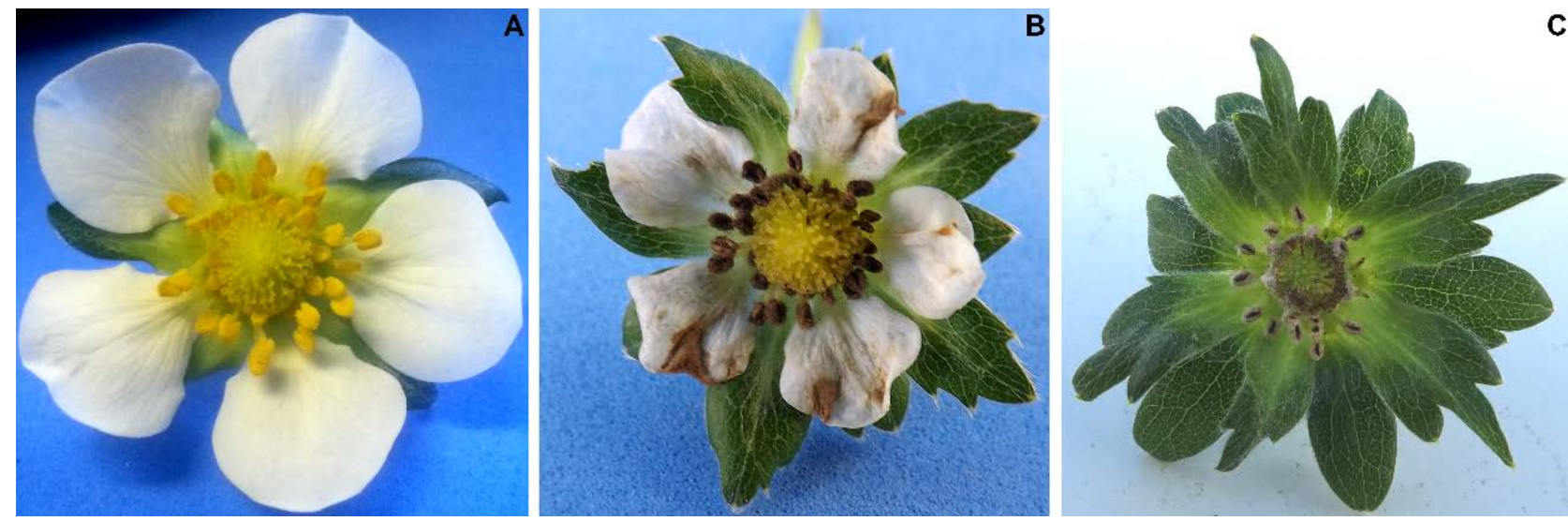

Fig. 1 - Anthers colonizing fungi in strawberry flowers. A Anthers without apparent fungal colonization. B Anthers colonized by fungi of the genus Cladosporium. C Anthers colonized by fungi of the genus Fusarium.
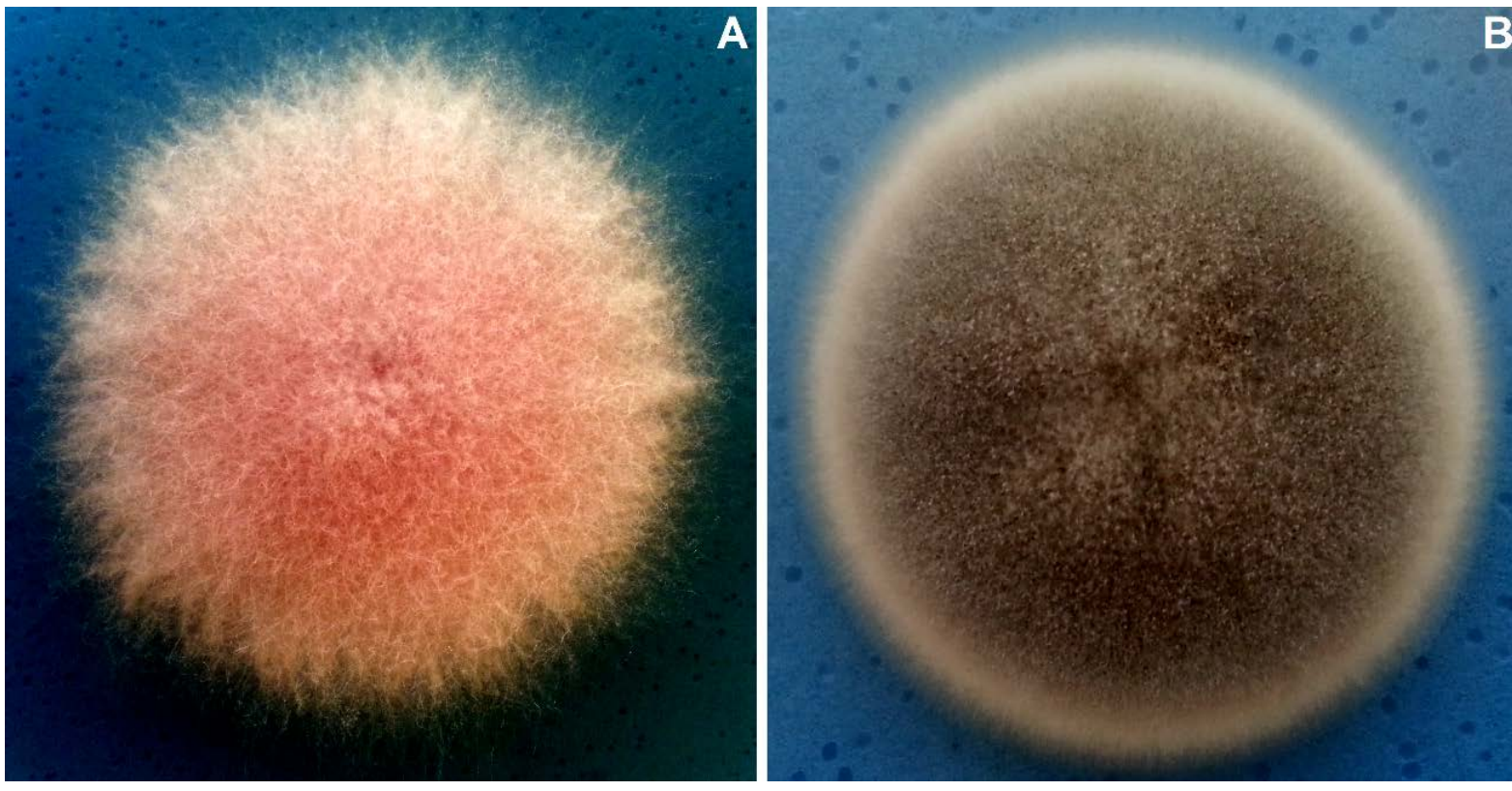

Fig. 2 - Mycelial growth of strawberry anther colonizing fungi. A Fusarium sp. mycelial growth in PDA (Potato-Dextrose-Agar) culture medium. B Cladosporium sp. mycelial growth in PDA culture medium. 


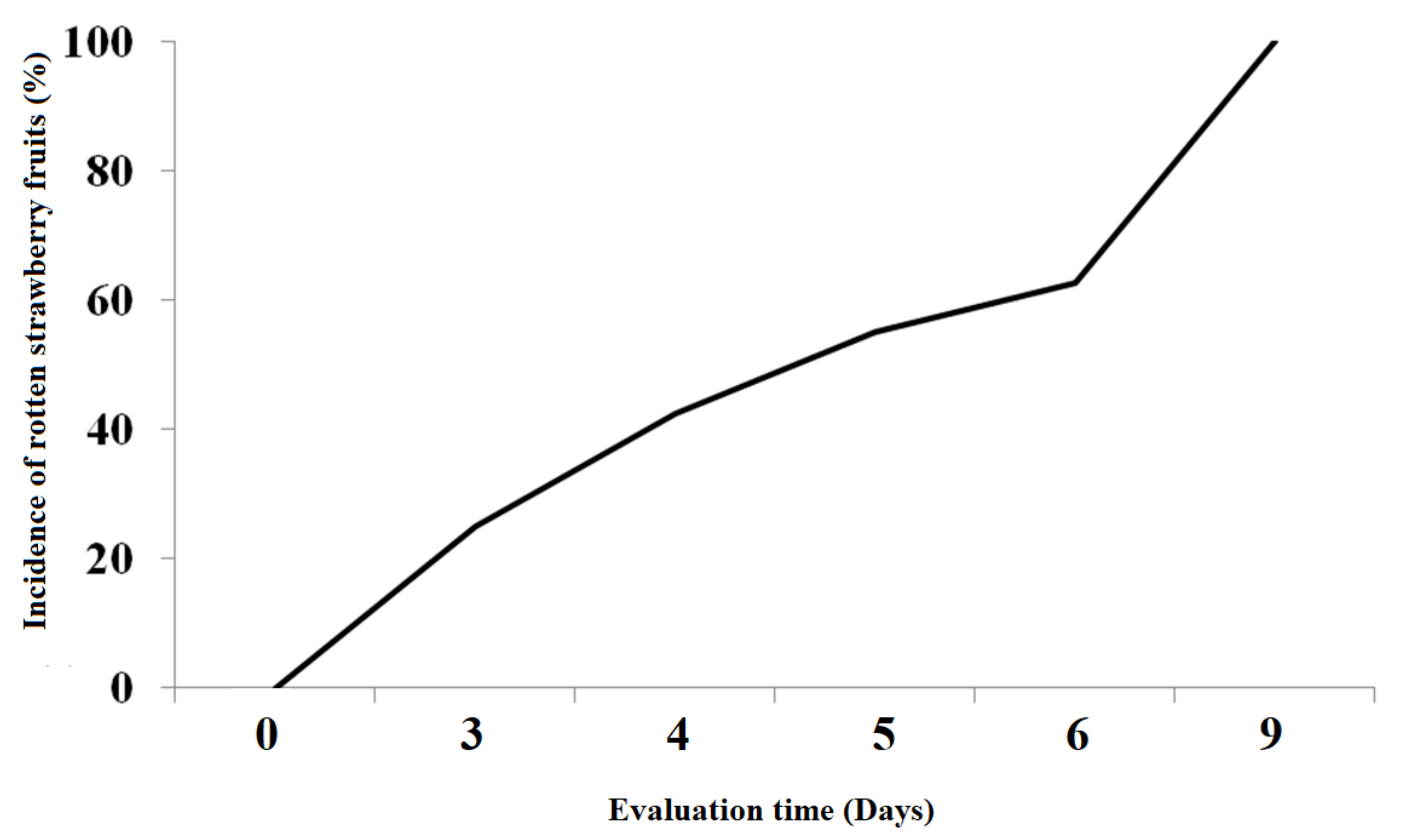

Fig. 3 - Incidence of Cladosporium rot in strawberry fruits caused by Cladosporium previously harboured in anthers.

\section{Discussion}

Cladosporium cladosporioides can cause the disease strawberry blossom blight, which is characterized by necrosis of flower that may lead to the production of small and malformed or misshapen fruits due to poor pollination (Gubler 1999, Nam et al. 2015). Black scab and dark brown sooty patches of leaves were also attributed to Cladosporium macrocarpum, Cladosporium tenuissimum and Cladosporium limoniforme (Ayoubi et al. 2017, Nam et al. 2015). On the basis of our results, the case of the fungus discussed herein seems to play a saprobic role (Koike et al. 2003) without causing any damage to the strawberry plants and its production.

Despite the negative visual appearance of the fungus-infesting anthers, there is no proven relationship between the incidence of fungus on the anthers and the increase in the number of deformed fruits or lack of pollination (Koike et al. 2003). We did not observe any fruit deformed and malformation related to the incidence of Cladosporium in the anthers. Neither any symptom related to leaves black scabs or typical blossom blight.

One question that has been raised by our research team is whether the presence of this fungus in flowers, even in a saprobic condition, could serve as a source of inoculum that would incite postharvest rot. Indeed, anther colonization may serve as a source of inoculum to incite postharvest disease, because colonized anthers remain attached to fruits. In our experiments, strawberries whose anthers were colonized by Cladosporium sp. showed rot caused by this fungus from five days after harvest.

Besides Cladosporium and Fusarium, fungi belonging to the genus Alternaria, Botrytis and Penicillium (also herein) have been found colonizing anthers in strawberry flowers (Koike et al. 2003). Since there are no active ingredients registered to control Cladosporium, other fungicides registered to $B$. cinerea and $M$. fragariae should be considered for flowers pulverization.

\section{Conclusion}

Cladosporium sp. was the most recurrent fungi isolated from the anthers. Fungi that grow in the anthers can serve as a source of inoculum for postharvest diseases. Azoxystrobin + diphenoconazole, boscalide + cresoxim-methyl, metconazole, methyl thiophanate, pyrimenthanil, tebuconazole and trifloxystrobin + tebuconazole were the most efficient chemical fungicides against the mycelial growth of Cladosporium sp. 

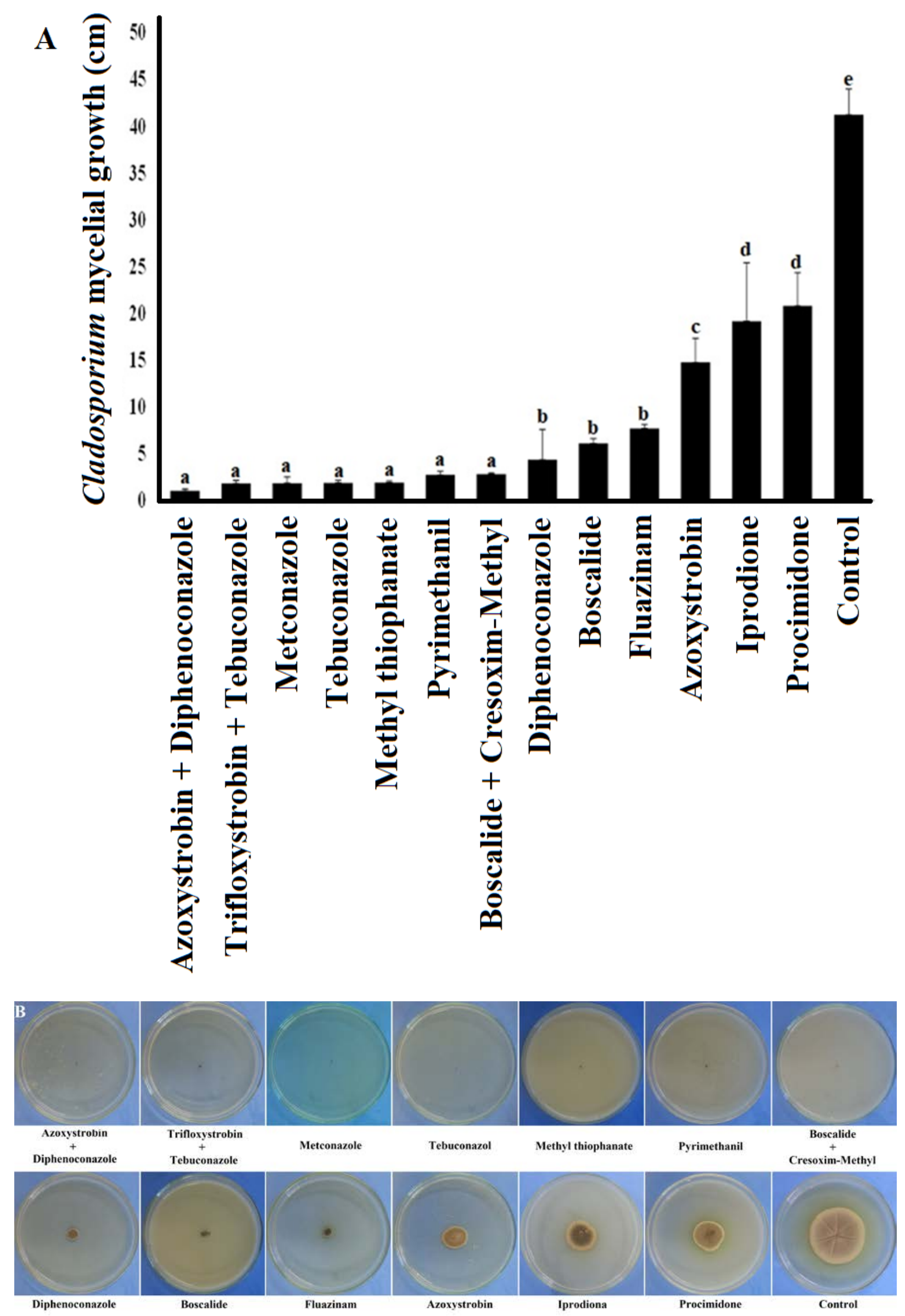

Fig. 4 - Proposal for chemical control of Cladosporium based on fungicides recommended to Botrytis cinerea and Mycosphaerella fragariae. A Fungicides against the mycelial growth of the 
Cladosporium at the recommended doses. B One of three replicates of fungicides treatments and their influence on the Cladosporium mycelial growth.

* The means were compared by the Scott-Knott statistical test at 5\% error probability.

\section{Acknowledgements}

Authors are thankful to Agricultural Research and Rural Extension Enterprise of Santa Catarina (EPAGRI) and Foundation for Research and Innovation Support of the State of Santa Catarina (FAPESC) for financing and encouraging the execution of the project that gave rise to this publication. The authors also would like to thank the technician Jonas Borba Pereira for its assistance on this study.

\section{References}

Ayoubi N, Soleimani MJ, Zare R. 2017 - Cladosporium species, a new challenge in strawberry production in Iran. Phytopathologia Mediterranea 56, 486-493.

Barnett HL, Hunter, BB. 1972 - Illustrated genera of imperfect fungi.

Campos MG, Bogdanov S, de Almeida-Muradian LB, Szczesna T et al. 2008 - Pollen composition and standardisation of analytical methods. Journal of Apicultural Research 47, 154-161.

FAO. 2019 - (Food and Agriculture Organization of the United Nations) FAOSTAT/Statistics Division. http://www.fao.org/faostat/en/\#data/QC (accessed 12 August 2019).

Gubler WD, Feliciano CJ, Bordas AC, Civerolo EL et al. 1999 - X. fragariae and C. cladosporioides cause strawberry blossom blight. California Agriculture 53, 26-28.

Kaczmarska E, Agnieszka MD, Hortynski JA 2008 - The influence of pollen viability on seed set and fruit mass in strawberry [Fragaria x ananassa Duch.]. Acta Agrobotanica 61, 79-84.

Koike ST, Vilchez MS, Paulus AO. 2003 - Fungal ecology of strawberry flower anthers and the saprobic role of Cladosporium cladosporioides in relation to fruit deformity problems. HortScience 38, 246-250.

Nam MH, Park MS, Kim HS, Kim TI, Kim HG. 2015 - Cladosporium cladosporioides and C. tenuissimum cause blossom blight in strawberry in Korea. Mycobiology 43, 354-359.

Woodson WR. 1991 - Genetics and Breeding of Ornamental Species. In Current Plant Science and Biotechnology in Agriculture, Eds. J. Harding, F. Singh \& J. N. M. Mol. Netherlands: Kluwer Academic Publ. pp. 317-331. 